\title{
The anatomy of written scam communications: an empirical analysis
}

This is the author's final, accepted version of the paper. A formatted version will be published in Crime, Media, Culture

(C) Elisabeth Carter 2015

\begin{abstract}
This paper examines the interactional construction of written scam communications. It draws on an empirical corpus of 52 envelopes containing letters and leaflets designed to deceive recipients into parting with their money or personal details, and presents the analysis of eight extracts in illustrating the findings. This research draws on interactional methodologies to provide in-depth insights into the underlying techniques used in scams, and to identify a wider framework that accommodates and facilitates their effect. It explores and exposes what elements of the scammers' communicative efforts are enlisted and directed towards the performance of particular acts such as inferring legitimacy and credibility, and inspiring urgency and secrecy. These elements combine to perform a range of highly effective communicative acts that, although the communication is mass-produced with no knowledge of the recipient other than a name and address, result in the exploitation of their individual vulnerability in a highly personalised manner.
\end{abstract}


Some research addresses a wide variety of scams specific to their context, such as internet romance scams (Koon and Yoong, 2013; Whitty and Buchanan, 2012), sales letters (Vergaro, 2004) and advance fee fraud emails (also known as Nigerian 419 scams) (Freiermuth, 2011a; Kich, 2005). Others address combinations of scam practices (Modic and Lea, 2013), use differing lists of acts to define scams or fraudulent practices (Mason and Benson, 1996; Titus and Gover, 2001), or approach scams by practice type, such as face-to-face or two-way communication (Langenderfer and Shimp, 2001). There is very little literature that focuses on postal scam communications. Unlike internetbased scams, which can involve numerous interactions between the scammer and the recipient, many mass-mailed postal scams are reliant on one communication to convey all the information to convince the recipient to part with their money or personal details. This distils the communicative process that would be achieved through numerous interactions into a single communication, which needs to persuade the recipient to trust the message it contains to the extent where they are prepared to respond with money or personal details. This paper examines the communicative strategies of these 'one-off' scams that make them so effective in this regard.

Credibility is 'an important, if not the basic building block of the scam operation' (Koon and Yoong, 2013: 37), and is shown through care, concern and prioritising the needs of others (Cockcroft and Cockcroft, 2005; Freiermuth, 2011b). Trust is similarly important (Dixon, 2005; Freiermuth, 2011b); indeed, in the absence of other information, the recipient will make their decisions based on their perception of the authority and trustworthiness of the sender (Selin, 2006). Self-disclosure and the removal of agency are also important: 'Performance is deemed more important than mere reputation or appearance in promoting trust... Performance is executed through words in the form of self-disclosure' (Henderson and Gilding, 2004: 492). Self disclosure manifests in the sender revealing some personal information, showing vulnerability or a personal flaw (Koon and Yoong, 2013). Disclosing personal, large or frequent amounts of information can reveal the sender's personality (Benwell and Stokoe, 2006), give the impression that they are honest (Higgins and Walker, 2012; Koon and Yoong, 2013), and that they trust the recipient with personal information, something which invites reciprocal trust. The removal of agency also enables the sender to demonstrate credibility, authority and trustworthiness without appearing to do so explicitly. It can be achieved by using credible sources (Bhatia, 2004) such as endorsements from previous winners (Clifton and Van de Mieroop, 2010), external measures of credibility and authority, such as qualifications (Bhatia, 1993), showcasing past achievements and successes (Higgins and Walker, 2012); it can manifest in requests being framed as requirements of a celestial or higher power (Koon and Yoong, 2013), or endorsed by authority figures (Whitty and Buchanan, 2012). Compliments indicate a social solidarity (Guerrero et al., 2011; Stevens and Kristof, 1995) that leads recipients to perceive the scammer has similar attitudes to them, which builds trust and increases their likelihood of responding (Silvia, 2005; Stevens and Kristof, 1995). A sender's promise of their future obligations also builds social bonds as they demonstrate the start of a social contract (Koon and Yoong, 2013). This enables scams to present a facade of legitimacy Jagatic et al., 2007), identified by the Office of Fair Trading (OFT) (2006: 20) as an important factor in victims 'falling for' scams. Flattery lowers a recipient's guard, and encourages them to trust the sender with personal information (Koon and Yoong, 2013). Personal pronouns can create a 'them vs us' frame (Higgins and Walker, 2012), which builds solidarity by aligning the sender with rather than against, or different from the recipient, and 'you' can construct the reader's identity and build feelings of solidarity with the sender (Ewald and Vann, 2003). 
Once a recipient of scam mail responds, commitment compels them continue to respond, send money, or whatever action they have committed to performing (Cialdini, 2001; Whitty and Buchanan, 2012). This overrides the victim's decision-making processes to the extent that they will continue to deliver on a prior commitment even if the original incentive for them to enter into that commitment is altered or removed (Freedman and Fraser, 1966). The decision to enter into an agreement, even if it is not a continuing commitment but is a one-off, is so powerful that the victim will be more likely to respond to subsequent requests from the same source (Modic and Lea, 2013). Kunst-Wilson and Zajonc (1980) claim this is true even if a stimulus (the scam mail) is only subliminally familiar. This is particularly important as, once a recipient becomes a victim, they are more likely to be specifically targeted by other scammers in the following 12 months by virtue of victims often being put on a 'suckers list' (OFT, 2006). The present research uses an interactional approach, empirical data and inductive analysis to identify interactional features that may be particularly effective in exploiting individual vulnerabilities of recipients. It identifies three broad frameworks (addressing immediate concerns, genre-mapping and scripting) within which these communicative efforts are rooted, and through which the distortion of recipients' decision-making is achieved. It reveals how the scammers' techniques align to each framework, and how appeals for credibility, secrecy, urgency and trust are performed within each framework's particular structure and focus.

The data is a corpus of 52 posted scam communications recovered by Hampshire Trading Standards from scam victims. As is often the case with victims of this type of crime, isolation from sources of advice is a key component of scam mail (Fraud Aid, 2014; Johnson, 2003; OFT, 2006; Operation Signature, 2013; , Think Jessica, 2015). The victims of the scams used as data in this paper were socially isolated, or, in order to fulfil the requirements of the communication, acted in secrecy and without consulting friends or family. Eight extracts are presented to illustrate the analytic findings, and any identifying features were anonymised prior to analysis.

\section{Analysis}

\section{$\underline{\text { Addressing immediate concerns }}$}

When a recipient receives a piece of mail they make a decision about whether to open it, whether to read it, continue reading it, or to throw it away. Decision-making is shaped and determined by the context, by the options available to the decision-maker, and by whether what they are reading confirms, fails to alleviate, or addresses their concerns. This early decision-making is important; the longer a recipient's exposure to and engagement with a scam, the more likely they are to suffer a degradation in decision-making and self-control, making them more vulnerable to falling victim to it (Baumeister et al., 2008). The following extracts demonstrate scam mail explicitly (extracts 1 and 4) and implicitly (extract 2) acknowledging concerns, and directly (extract 1 ) and indirectly (extract 3 ) addressing them.

Extract 1: You don't believe it! Do whatever you want... But read this letter anyway which is worth its weight in gold! 
Rather than attempting to dispel any concerns, the scammer explicitly acknowledges that the recipient will doubt the content of the letter ('You don't believe it!'). Extract 1 creates the illusion that the recipient is in control and they have decision-making options available to them, appearing to allow the recipient to choose their course of action ('Do whatever you want'). Scam prevention and awareness-raising literature often includes warnings about being pressured; however, the interaction here appears to provide options to the recipient and appears open by acknowledging the content will be unbelievable. This openness also builds trust, as by acknowledging the recipient will doubt his message, and exposing the potential for the recipient to discard the letter, he shows vulnerability (Higgins and Walker, 2012; Koon and Yoong, 2013). The use of 'you' constructs the reader's identity (Ewald and Vann, 2003) as someone who doubts the letter, while also implicitly communicating that doubt is an unproblematic, expected response. Anticipating the recipient's doubt and the use of 'you' give the appearance that the letter is personalised, which builds rapport and increases scam compliance (Modic and Lea, 2013), and is reassuring as it demonstrates the sender is authoritative and knowledgeable, and unlike the persona found in scam awareness-raising literature. The scammer uses the recipient's constructed identity as a foundation on which to issue an instruction (to read the letter despite their disbelief). This encourages the recipient to continue reading, making them more vulnerable to the scam as, the more time recipients invest in a scam, the more likely they are to respond to it (Baumeister et al., 2008). The final 'which is worth its weight in gold' also makes the recipient more vulnerable to the scam as it is an appeal (albeit indirect) to the recipient's visceral desires (Langenderfer and Shimp, 2001).

Extract 2: Mrs. Rachel Nibbs... Can confirm everything. In spite of all her doubts she requested the... And became rich shortly afterwards.

In extract 2 the scammer also avoids denying the presence of doubt, enabling him to avoid having to justify why the recipient should not have doubts. Differing from extract 1 however, here the scammer asks the recipient to ignore their doubts in a more indirect manner, communicated through discussing the experience of a previous respondent. References and testimonials are used by scammers to support their claims, bolster their credibility and legitimacy (Clifton and Van de Mieroop, 2010; Ross and Smith, 2011). This removal of agency enables the scammer to distance himself from ownership of the message and lends it legitimacy as it is drawn from the experience of someone other than the sender. It also reassures the recipient that others have had doubts similar to their own, but responded regardless and were rewarded. Perceiving a similar experience to another builds trust and feelings of solidarity (Silvia, 2005; Stevens and Kristof, 1995), and legitimises the belief that if they act in the same way they will also receive the rewards, as part of an implicit social contract (Jagatic et al., 2007; Koon and Yoong, 2013). This encourages the recipient to suspend their disbelief and ignore their immediate concerns. The use of the phrase 'all her doubts' also suggests a range of doubts, which enables the recipient to personalise the message to their own situation, which increases scam compliance (Modic and Lea, 2013). Recognising the recipients' concerns, the removal of agency, and the implicit promise of visceral rewards combine to reassure 
the recipient and make them vulnerable to the scam without it performing high visibility behaviours such as pressurised selling.

Extract 3: Trust Amy Denver. I am sure you too will benefit from a new, marvellously happy life.

Unlike extract 2, the testimonial in extract 3 it is a direct endorsement of the sender (Amy Denver). The 'otherness' of the testimonial is used to reassure the recipient and show that the sender is trustworthy, without her appearing to do so herself. It sends the message that if the recipient doesn't know if they can trust the sender, they can trust the opinion of someone who has received rewards by responding. Trust statements are influential in recipients' decision-making (Selin, 2006) and increases their predication to becoming a victim (Freiermuth, 2011a). However, the trust statement here is particularly powerful as it incorporates a testimonial as evidence of the sender's trustworthiness (Bhatia, 2004; Clifton \& Van de Mieroop, 2010), and does not require the sender's opinion to come under scrutiny. Similarly to extracts 1 and 2, the sender does not directly ask the recipient to trust her; the testimonial enables him to directly issue an instruction to the recipient without appearing to pressurise or instruct the recipient. The use of 'you' builds a connection (Higgins and Walker, 2012) between the recipient and the previous respondent, by aligning them both with trusting the sender and a positive outcome. Unlike the riches and wealth of extracts 1 and 2, the reward is 'a new, marvellously happy life'. This reflects Langenderfer and Shimp's (2001) findings that scams appeal to recipients' desires, which vary with their motivations (loneliness, misfortune, poverty, greed; also discussed by OFT, 2006). Extract 3 is likely to influence and exploit vulnerable recipients by appealing to those who would consider their current situation unpleasant or unhappy and seek a new or happy life. A range of unfortunate life circumstances such as bereavement, estrangement, job loss, financial worries and so on leave individuals particularly vulnerable to taking risks (Anderson, 2013). Recipients motivated to change their circumstances are made more vulnerable to suggestion (Langenderfer and Shimp, 2001), particularly if the scam appears to be specifically directed towards their situation (Modic and Lea, 2013).

Extract 4: I know that many so-called clairvoyants and others have sold you and other honest people genuine fairy tales. I am sorry to be so blunt, but I do not sit at the same table as these charlatans. You can believe me and offer me your trust.

Extract 4 directly positions the sender as different from scammers and reinforces his position as a credible and legitimate psychic. It shows the recipient that the sender has awareness of scams, articulated through his descriptions of people being 'sold' 'fairy tales' by 'so-called psychics' and 'charlatans'. By mentioning scams the sender shows that he is not concerned about the recipient thinking about scams, and doing so while claiming to be a clairvoyant himself gives the impression that he is open, honest and does not like scammers; types of self-disclosure that might reassure the recipient and engender their trust. If the recipient has been scammed previously, the sender's apparent knowledge of this ('I know that many so-called clairvoyants and others have sold 
you... genuine fairy tales') reinforces his legitimacy as a psychic, and makes the communication appear personalised to the recipient, which increases their likelihood of compliance (Modic and Lea, 2013). Drawing on a 'them vs. us' frame (Higgins and Walker, 2012), the scammer uses 'I' to position himself as different from the 'charlatans', and 'you' to reinforce his solidarity with the recipient (Ewald and Vann, 2003). His apparent care for the recipient reinforces his credibility (Cockcroft and Cockcroft, 2005); this and the contrast he sets up between the 'charlatans' and himself imply that he is of good character. The sender's apology ('sorry') shows his reticence to speak unkindly of others, but also that his principles are to speak out against imposters. He shows his vulnerability by being blunt, exposing his feelings and revealing this aspect of his personality (Benwell and Stokoe, 2006; Koon and Yoong, 2013). His apology could also refer to his direct appeal for belief and trust, enabling him to produce this important element in persuading recipients into victimhood (Freiermuth, 2011b) while remaining unassuming. The communication manages the potential difficulty of a recipient's previous unsuccessful response to similar letters, which may trigger heightened immediate concerns, by relying on the existence of previous scams to reassure the recipient and demonstrate this sender's trustworthiness, legitimacy and knowledge.

\section{Discussion}

The framework of addressing immediate concerns is reminiscent of Hutchby's (1992) 'routine scepticism' in talk radio interaction; however, in scam interaction it manifests as an effect of the scammer anticipating and attempting to mitigate the recipient's scepticism, rather than as a feature of a talk radio interviewer's argumentative talk. In talk radio the interaction is also based on an adversarial framework of talk (Hutchby, 1992), and one where the parties interact, rather than the one-sided interaction that aims to establish trust that typifies the scam mail discussed in this paper. Written scam communications also rely on secrecy, and being received by the victim and not overseen by anyone else, whereas talk radio discourse is designed for an overhearing public audience. The scammer addresses the recipient's immediate concerns by explicitly and implicitly acknowledging them using combinations of 'you' and 'them vs. us' frames to personalise the communication and construct and address the recipient's problems. Delivering these messages directly, or indirectly through the removal of agency, the scammer uses self-exposure to reveal his vulnerability and garner the recipient's trust. These elements legitimise the communication and demonstrate the sender's credibility, authority and trustworthiness in combinations that are directed towards addressing the recipient's concerns. These elements are also present in the following extracts, but as they draw on situating the communication within frameworks or genres that are familiar to the recipient, the messages manifest and are delivered in different ways.

\section{Genre-mapping}

Genres are used to 'package our speech and make of it a recognisable response to the exigencies of the situation' (Berkenkotter and Huckin, 1995: 7). As identified in extracts 1 to 4, the sender expects the recipient to have doubts and concerns and to question the veracity of the communication. They therefore seek reassurance and evidence as part of the decision-making process, particularly if they are anxious (Maitlis and Ozcelik, 2004), and will focus on elements they recognise and are familiar 
with in order to decide if the communication is genuine and if they can trust it. Indeed, people are more likely to trust communications that are familiar to them or they have been exposed to previously (Zajonc, 2001). Consumer activeness is associated with vulnerability to scam solicitations (Titus and Gover, 2001), and older people are particularly vulnerable to difficulties in decision making based on advertising (Shivapour et al., 2002; Yoon et al., 2009). Using images and words familiar to the recipient may therefore enable the scammer to exploit existing bonds the recipient feels towards legitimate sources of information such as newspapers, celebrity interviews, recommendations and testimonials from previous winners or happy customers. These endow the sender with a facade of independent legitimisation which stimulates recipients' trust in the sender and the scam. Using familiar genres to deliver messages can override or divert rational decisionmaking processes; decision-making based on familiarity precedes decision-making based on judgement and logic, and once a judgement has been made, the recipient will then seek to rationalise (Zajonc, 1980). This analytic section draws on a combination of a case study approach and individual examples, in order to capture and reflect the individual, myriad and interwoven techniques used by scammers when drawing on genre-mapping in scam communications.

\section{Case study}

The scam is from a sender who claims he is a psychic named 'Master Cosmos', writing to the recipient in order to pass on an inheritance from Robert, a wealthy director of gaming casinos in Las Vegas. The story is that prior to embarking on an expedition, Robert told Cosmos that, if anything should happen to him, an item (variously described, but in essence a chest of riches) should be passed on to the recipient of the scam mail ${ }^{1}$. Alongside the scam letter detailing this, there is also a 'handwritten' (typed in a handwriting style typeface) letter from Robert on headed notepaper, explaining the situation and asking Cosmos to carry out his final wishes if he were to go missing. Other inserts are a 'newspaper' clipping from 'The reporter' that details Robert's disappearance, and a 'candid interview' clipping from 'Clairvoyance mag No.72'. Newspapers are pervasive, familiar and often trusted sources of information; a newspaper clipping lends credibility to the communication and engenders trust in the recipient. It also increases the impression of credibility through implying that the information in the scam letter can be confirmed through triangulating the multiple pieces of implicitly and explicitly corroborating evidence provided. This exploits Zajonc's (2001) claims that decisions are made through feelings of familiarity, and these are then sought to be rationalised through evidence. Additionally, the removal of agency involved in using a newspaper clipping to deliver implicit messages of credibility (Bhatia, 2004) means the sender can assert this quality in themselves and the letter without explicitly doing so. The presence of an insert itself is also an implicit way in which the scam draws on genuine communications; inserts are widespread in magazines and newspapers, and their presence in scam mail can legitimise or lend it credibility.

\footnotetext{
${ }^{1}$ Although the recipient's name had been used throughout the communication, it had not been printed on the additional slip of paper included alongside the letter, and 'you know who' had been used instead, perhaps, as this was a separate inserted piece of paper, mail merging each recipient's name onto that insert and then matching up the inserts with their associated letters would have been too time and resource intensive. This could provide an insight into how the scammers manage the large numbers of different recipients, whilst trying to maintain the impression that the communication is intended for that one recipient.
} 
The 'candid interview' with the sender enables him to show that he is important and successful enough to warrant being interviewed, and used to demonstrate his legitimacy (Higgins and Walker, 2012). It also shows that he is in demand for his services, which demonstrates his authority and credibility (Bhatia, 1993), and that he is trusted by others: 'I cannot speak about my more distinguished political or artistic consultants. Except perhaps Arnold, Sylvester and George, but they are close friends.' This interview also shows the sender revealing information about himself and protecting his personal life 'I am married... but this remains part of my Ultra Private sphere. I don't want my wife or children to be bothered by my fame... or by your article.' This self-disclosure and revealing his personal as well as professional sides engenders trust in recipients, and shows his credibility (Benwell and Stokoe, 2006; Cockcroft and Cockcroft, 2005) by demonstrating that he values personal information and he prioritises their privacy over his self-publicity. Using otherness relieves the sender from the responsibility of the content of these inserts and enables the sender to deliver these key messages without having to do so explicitly, which is less likely to be believed than if it is done by a third party.

As seen in extracts 2 and 3, the use of testimonials are a way in which the credibility and legitimacy of the sender can be established and reinforced. When performed within a 'genremapping' framework, these are further strengthened by being framed within a context that is familiar to the recipient. This is extended to the scammer's use of celebrity names when alluding to previous clients in order to demonstrate his position as an authority in the field - not only as a psychic, but one that rich and important people go to. This provides an additional impact to testimonials, and enables the reader to assess the sender's credibility as they may feel as if they know and trust the celebrities referred to as they are familiar names. Trustworthiness and expertise are delivered through testimonials, and although the newspaper clipping does not involve a direct testimonial from a celebrity, it affects the reader's perception (Ohanian, 1990) as celebrity endorsements increase the credibility of the message being delivered (Cugelman et al., 2008). The 'otherness' associated with using 'third party' speech and recommendations (Bhatia, 2004; Clifton and Van de Mieroop, 2010) enables the sender to communicate indirectly to the recipient. This otherness legitimises the content (Bhatia, 1993); it is enacted by the sender communicating with the interviewer, with the recipient as the overhearing party, ostensibly not for the purpose of trying to convince the recipient.

By genre-mapping multiple sources, the sender shows the recipient he is fulfilling a commitment to a third party, rather than contacting the recipient for his own ends, while also highlighting that the communication is unique and special to the recipient, which increases compliance (Modic and Lea, 2013). The recipient is enlisted in assisting the sender to fulfil this commitment, and in doing so will receive the riches that are bequeathed to him. By writing to the recipient the sender is fulfilling his obligation, which in turn compels the recipient to reciprocate as part of an implicit social contract (Jagatic et al., 2005; Koon and Yoong, 2013). This tactic is particularly persuasive due to the elements of altruism and delivering a man's final wishes, and due to this approach avoiding scam tactics of which recipients may be aware and that may draw concern. These include requests for money or direct orders for action (Blanton, 2012); instead the recipient is asked to enable a commitment to be honoured and for destiny to be enabled. It also addresses other potential causes for concern, such as a lack of official documentation to support its claims (Grabosky and Duffield, 2001). Explicit appeals for secrecy, in particular, requests or demands for secrecy are unusual and not found in legitimate communications, other than in private communications. Indeed, 
appeals for secrecy are often cited as a warning sign of a scam (Scambusters, 2014). The unusual nature of appeals for secrecy and their potential to raise concern is however mitigated through scams genre-mapping secrecy in the contexts in which they are least likely to draw attention as unusual.

Extract 5: This is a personal letter. It contains secrets between us.

Extract 5 draws on secrecy as an act between two people on a personal level, and reframes the letter as a personal one, and the secrets as mutual. This implicitly suggests that the recipient has some level of intimacy and shared trust with the scammer, reinforced through the use of 'us'. This increases the recipient's perceptions of its legitimacy and therefore its chances of success in scamming the recipient (Higgins and Walker, 2012). The self-disclosure of secrets suggests that the recipient is being put in a position of trust by the sender (Henderson and Gilding, 2004), which implicitly suggests that the recipient should respond in kind (Koon and Yoong, 2013).

\section{Discussion}

This section has revealed how scam mail draws on key elements of genuine consumer-directed communications in order to deliver messages that are persuasive, direct and could otherwise cause alarm or concern. Rather than directly or indirectly addressing any particular concerns the scammers anticipate the recipient will have (as in extracts 1 to 4), the communication within the genremapping framework focuses on demonstrating the sender's credibility, trustworthiness and legitimacy through the removal of agency and relying on 'legitimate' sources of information. Simulating genuine communications and using elements of genres that are genuine and familiar to the recipient in order to deliver messages to them is similar to a suspect drawing on elements of truth in attempting to deliver a story in a police interview while disguising the lies (Carter, 2014). It exploits recipients' innate decision-making processes (Zajonc, 1980) that are based on familiarity and enables the scammer to put pressure on the recipient and engage in appeals for trust, urgency and secrecy that could not happen during addressing the recipient's concerns. The differences between the communicative strategies used within the two frameworks illustrate how scam communication is tailored to the different requirements of the recipient at each stage of decision-making. It exposes these differences as proactive actions taken by the scammer in order to attend to recipients' shifting levels of vulnerability and vigilance.

\section{Scripting}

The previous two sections have shown how the recipient's immediate concerns are addressed or suspended, and how evidence for the sender's credibility and the offer's legitimacy is provided through drawing on genre-mapping respectively. This final analytic section explores how the sender uses scripting in directing the recipient towards a course of action. The recipient is given a new role 
and identity as a winner, someone in control of their destiny, someone with good luck, the receiver of a gift, and so on. The recipient may be unfamiliar with this new identity, but it is welcome and seated within a largely familiar context; all the recipient needs to do in order to achieve it is to follow the script provided. The following extract is from the final paragraph of the scam explored in the case study. The recipient is provided with a specific and multifaceted form of words to which they are invited to agree (by ticking the box), written from the perspective of them communicating with the scammer.

Extract 6: $\square$ YES, Master Cosmos, please send me the wonderful Secret Container which was entrusted to you for me by our friend Robert, the Director of Gaming Casinos which makes hundreds of millions of pounds every day. What a joy to receive a Gift of Great Value and have the authorization to open this Heavy Chest.

The multifaceted elements of this extract enable the sender to script the victim on various levels. By ticking the box, the recipient agrees that the container exists, the situation described to them in the scam letter is real, and that they believe the secret container is 'wonderful' and 'a joy to receive'. This shows the scammer scripting the recipient's description of, and emotions towards the object, even though the recipient has not seen or been told precisely what its contents are, and it is named variously here as a 'Secret Container' and a 'Heavy Chest'. The recipient is scripted to construct the relationship he has with both Cosmos and Robert; Robert is described as a mutual friend ('our friend Robert'), whereas the recipient would not have had any friendship with or prior knowledge of either party (and they are vehicles of the scam, no doubt fictional creations of the sender). The use of first name terms indicates a friendship between the recipient and the benefactor, and the sender and the benefactor. Having a mutual friendship reinforces the credibility of the third party (the sender), as it suggests a mutual social bond, a state that increases the recipient's perception of legitimacy (Jagatic et al., 2007). The otherness of the mutual friend provides an external ratification of the sender's trustworthiness (Bhatia, 1993); by being entrusted by an important person with his last wishes in the form of passing his riches on to the recipient. The recipient is scripted to describe the turnover of the company ('hundreds of millions of pounds every day'), which is again something the recipient would have had no knowledge of (and is a fictional vehicle of the scam). It is in this way the sender can lead the recipient to express that the company is real, the people Master Cosmos talks of (including Cosmos himself) are real, and the secret container is real and about to be his.

The following extracts involve indirect scripting as the recipient is directed towards a course of action, rather than the words themselves being dictated to them for them to agree to. In extract 7 , the scripting is also situated within a spiritual framework, and shows how the recipient is scripted in his words and actions, and that these are specific and time-limited.

Extract 7: After pronouncing this verse out loud, return this extremely sacred image within 24 hours. 
Although the extract itself issues instructions to the recipient, these direct the recipient to carry out tasks that then directly script their spoken words and further actions. By situating this instruction within a spiritual and ritualistic framework, the scammer is able to explicitly direct the recipient to respond and to do so quickly; it enables him to convey a sense of urgency (which leads recipients to respond without due consideration; OFT, 2006), but without causing alarm in terms of directly pressuring the recipient himself. This 'otherness' (Koon and Yoong, 2013) instead frames the request as a sacred requirement by others in order to enact a particular outcome beneficial to the recipient, rather than a need of the sender to hurry the recipient into responding. By situating the urgency as part of a time-bound ritual, or as part of a predetermined time-limited celestial requirement, the sender is able to remove himself from the authorship of the request.

Extract 8: Hurry - such an opportunity will probably never come around a second time and you would regret it for the rest of your life.

Extract 8 also articulates the urgency required of the recipient although, unlike extract 7, this is not situated within a ritual or enacted through otherness, but is instead framed as an attempt to alert the recipient and advise them to take up the offer before it expires. This is a familiar sales technique, seen in advertising, for example 'hurry while stocks last!', and is personalised to the recipient through the use of 'you' and 'your'. This makes the responsibility for the later regret that will befall the recipient very specific to them and their immediate situation, rather than one that is abstract or uncontrollable. The underlying threat associated with this statement is mitigated by it being situated in a framework of concern; the sender does not want the recipient to regret being too late in taking up the offer (which it is implied will be the inevitable outcome if he is not quick enough to respond). Indeed, the sender demonstrates his credibility in showing concern for the recipient (Cockcroft and Cockcroft, 2005) and that he cares about their future happiness. Extract 8 also shows how the recipient's decision-making can be skewed by the sender; the issue of whether the recipient will respond or not is not in question - the statement suggests it is only a case of whether the recipient will do so in an expedient enough fashion.

Extract 9: We are anxious to receive your documentation. Please be prompt!

In extract 9 a delay is categorised as something that will cause anxiety to the sender and their associates. This self-disclosure shows the sender as vulnerable (to delays), which reveals honesty (Higgins and Walker, 2012) and engenders trust in the recipient (Koon and Yoong, 2013). The sender also presents a facade of credibility by displaying an anxiety for the recipient, shown through his concern (Cockroft and Cockroft, 2005) that they respond quickly enough to receive the prize. The content of this extract encourages the recipient to respond promptly, and it is important to note that the sender frames their anxiety as linked to the speed of the recipient's response, 
rather than associated with the potential for the recipient not to respond, which echoes the underlying message of extract 8 . The absence of a question as to whether the recipient will respond removes the option of not responding from the recipient's frame of reference and implicitly suggests their response is inevitable.

\section{Discussion}

Scripting can manifest in direct and indirect forms, and from first and second person perspectives. It narrows the decision-making options available to the recipient and makes it easier for the sender to mitigate explicit directions for expediency, or direct a recipient towards a course of action without appearing to issue orders to do so.

\section{Conclusion}

The three frameworks of addressing immediate concerns, genre-mapping and scripting all accommodate a variety of communicative techniques that are used by scammers to inform, persuade, convey credibility, demand urgency and secrecy, and provide reassurances of legitimacy, in ways which address the individual and localised requirements and concerns of the recipient. They also enable recipients' decision-making processes to be manipulated and their perceptions redirected or distorted, while mitigating their doubts or concerns. The sender attempts to reassure the recipient through acknowledging and addressing their immediate concerns, for example through testimonials from previous responders. Familiar communicative techniques and genres are used to deliver messages, provide evidence for claims and mitigate potentially alarming elements. Finally, clear directions are given for the recipient to follow in order to complete the process.

Although trust, credibility, urgency and secrecy are key facets of scam mail, not all are present within each of the three frameworks, which suggests that they are distinct from one another, with different communicative objectives and properties. Appeals for urgency and secrecy are not present in addressing immediate concerns, as the nature of urgency and secrecy do not align with its focus of quelling immediate fears or convincing the recipient to suspend them long enough to continue reading. In genre-mapping, the focus of the extracts appears to be the use of evidence to ratify and legitimise the communication as genuine, rather than issuing direct appeals to the recipient; therefore, appeals for urgency do not appear. Genre-mapping does enable appeals for secrecy that appear legitimate, for example through genre-mapping personal communications between friends (extract 5). Urgency is conveyed in scripting through the use of ritualistic contexts to rationalise the request (extract 7), or through concern for the recipient (extract 8). Rather than appearing as direct appeals for secrecy, the nature of scripting means secrecy is implicitly inferred through the description of the rewards (extract 6), and through the sacred nature of rituals (extract 7). Attempts to establish the credibility of the sender and the offer are present in addressing immediate concerns through references and testimonials (extract 2), otherness (extract 4), and care and concern for the recipient (extract 4). In genre-mapping credibility is established through using familiar and trusted sources of information (newspaper clipping from the case study) and advertising techniques (extracts 8 and 9), multiple sources of evidence (case study) and the removal of agency 
(newspaper clipping in the case study). Addressing credibility is absent from scripting, as credibility is something that emanates from the source rather than the recipient. Trust statements and appeals for trust appear in addressing immediate concerns, although these are either implicit or mitigated by an apology for directness (extract 4), or are delivered through another source (extract 3). Where trust does not feature, this may be because the statement is addressing a different immediate concern, such as disbelief (extract 1 ) or doubt (extract 2). Trust is more pervasive in implicit ways; by acknowledging the recipient will doubt the letter (extracts 1 and 2), delivered through a third party (extract 3), through self-disclosure or in a display of vulnerability (extract 4). In genre-mapping, trust is enacted through exploiting existing bonds recipients have with familiar sources of information and their communicative styles (newspaper clipping in the case study and extracts 8 and 9), selfdisclosure to a third party (interview in the case study), testimonials (interview in the case study) and through the suggestion of intimacy with the recipient (extract 5).Trust is sought within the framework of scripting through self-disclosure (extract 9), the presence of a mutual friendship and through the scammer being trusted by a third party (extract 6 ).

The use of 'you' is important as it is used to display knowledge and to identify the recipient's potential concerns in constructing the reader's identity (extract 1), to give the illusion that the recipient has control and a range of decision-making options available to them (extract 1), or conversely, reinforces the specificity of the offer to that recipient and identifies them as personally responsible for their destiny (extract 8). Using 'you' to personalise the communication reinforces the sender's close and individual connection with the recipient (extracts 1, 3, 4, 6, 8 and 9), and constructs the recipient's problems or concerns (extracts 1 and 4). The removal of agency is significant in addressing immediate concerns as it implicitly reinforces the credibility and trustworthiness of the sender. This is often enacted through the use of personal (extracts 2 and 3 ) and professional testimonials in a range of formats (interview and newspaper clipping in the case study). Otherness or the removal of agency is used in direct scripting (extract 6); although the sender provides the words for the recipient to agree to, it is ultimately the recipient that becomes the author of the words. It is also used indirectly through the actions required of the recipient being framed as the needs of their new role (extract 7).

Self-disclosure is a useful tool through which scammers can deliver the message that they are trustworthy; by revealing a weakness or a personal side they are inviting the recipient to identify with them or reciprocate in kind. Self-disclosure reveals vulnerabilities which would, by their nature, be expected to be encountered in later stages of interaction, rather than in earlier stages, where the focus is on convincing recipients to suspend their disbelief. Self-disclosure and otherness are performed through the use of evidence (interview and newspaper clipping in the case study) that are intended to be interpreted as 'authored by others'; this removal of agency is used to deliver messages of the sender's legitimacy and credibility without the sender appearing to do so himself. The presence of inserts also shows that the communication is credible enough to contain them. Selfdisclosure only occurs in implicit (extract 9) rather than the explicit scripting, which reflects the different perspectives scripting can take; explicit scripting attends to the words of the recipient (extract 6) while the implicit attends to the role of the recipient and what they will need to do to receive the reward (extracts 7,8 and 9 ).

Scam mail is highly flexible and has the ability to appear to be directly and specifically written for the recipient, whereas in reality, identical letters will have been sent to hundreds or 
thousands of addresses. It has transformative abilities insofar as it enables a variety of potential concerns to be addressed, it can communicate with the recipient in a manner that is familiar and reassuring to them, and it can issue instructions, directions and threats in a framework that makes them appear reasonable rather than alarming. Importantly, this enables many of the key features that are described as warning signs for potential scam mail victims (pressure to respond, calls for secrecy, requests for money) to be addressed both explicitly and in more subtle ways, through the use of 'you', self-disclosure and the removal of agency. These, together with trust, credibility, secrecy and urgency, are represented and promoted in different ways, which have been identified in this paper as linked to the discrete frameworks of addressing immediate concerns, genre-mapping and scripting. Examining scam communication as a collection of detailed and specifically employed interactional strategies employed within, and linked to, wider strategic frameworks makes it possible to gain an understanding of scam interaction that is different from the literature which differentiates interaction on the broader basis of scam type. This paper proposes these frameworks are the building blocks of the interactional construction of scam communication more widely and provides insights into the criminal requirements of the scammers who create them. The differing frameworks enable the scammer to convey messages across the spectrum of explicitness, directness and persuasion that would ordinarily be delivered through a number of interactions with the recipient (for example, in romance scams; Koon and Yoong, 2013), and therefore in this research have been identified as the way in which scammers manage the restrictive nature of single speculative postal scam communication. 
References

Anderson KB (2013) Consumer Fraud in the United States, The Third FTC Survey. Staff Report of the Bureau of Economics Federal Trade Commission. Stanford University: Financial Fraud Research Center, Center for Longevity.

Baumeister RF, Sparks EA, Stillman TF and Vohs KD (2008) Free will in consumer behavior: Selfcontrol, ego depletion, and choice. Journal of Consumer Psychology 18(1): 4-13.

Benwell B and Stokoe E (2006) Discourse and Identity. Edinburgh: Edinburgh University Press.

Berkenkotter C and Huckin T (1995) Genre Knowledge in Disciplinary Communication. Hillsdale, NJ: Lawrence Erlbaum.

Bhatia VK (1993) Analyising Genre: Language Use in Professional Settings. New York: Longman Publishing.

Bhatia VK (2004) Worlds of Written Discourse. London: Continuum.

Blanton K (2012) The rise of financial fraud: Scams never change but disguises do. Center for Retirement Research 12(5): 1-12.

Carter E (2014) When is a lie not a lie? When it's divergent: Examining lies and deceptive responses in a police interview. International Journal of Language and the Law/Linguagem e Direito 1(1): 122140.

Cialdini RB (2001) Influence: Science and Practice (4th ed.). London: Allyn \& Bacon.

Clifton J and Van de Mieroop D (2010) 'Doing' ethos-A discursive approach to the strategic deployment and negotiation of identities in meetings. Journal of Pragmatics 42: 2449-2461.

Cockcroft R and Cockcroft S (2005) Persuading People: An Introduction to Rhetoric (2nd ed.). London: Palgrave Macmillan.

Cugelman B, Thelwall M and Dawes P (2008) Website credibility, active trust and behavioural intent. In: Oinas-Kukkonen H, Hasle $\mathrm{P}$, Harjumaa $\mathrm{M}$, Segerståhl $\mathrm{K}$ and $\emptyset \mathrm{hrstr} \varnothing \mathrm{m} \mathrm{P}$, Persuasive Technology: Proceedings from the Third International Conference, Persuasive 2008: 47-57.

Dixon $\mathrm{R}$ (2005) Nigerian cyber scammers. LA Times. http://www.latimes.com/la-fgscammers20oct20-story.html\#page=1 [accessed 28/01/15].

Ewald HR and Vann R (2003) 'You're a guaranteed winner': Composing 'You' in a consumer culture. Journal of Business Communication 40(2): 98-117.

Fraud Aid (2014) http://www.fraudaid.com/about/the_sounds_of_silence.htm [accessed 13/01/2015].

Freedman JL and Fraser SC (1966) Compliance without pressure: The foot-in-the-door technique. Journal of Personality and Social Psychology 4: 195-202. 
Freiermuth MR (2011a) This transaction is $100 \%$ risk free! Why do people fall prey to email scams? The proceedings of the inaugural LANCOMM (International Conference on Language and Communication) 2011, 'Embracing challenges in current trends': 235-242.

Freiermuth MR (2011b) Text, lies and electronic bait: An analysis of email fraud and the decisions of the unsuspecting. Discourse and Communication 5(2): 123-145.

Grabosky P and Duffield G (2001) Red flags of fraud. Trends and Issues in Crime and Criminal Justice 2000. Canberra: Australian Institute of Criminology. Available at: http://www.aic.gov.au/documents/7/1/8/\%7B718579b2-a97b-4719-b2ad01375403d4c4\%7Dti200.pdf [accessed 10/10/14].

Guerrero LK, Andersen PA and Afifi WA (2011) Close Encounters: Communication in Relationships (3rd ed.). Thousand Oaks: SAGE Publications.

Henderson S and Gilding M (2004) 'I've never clicked this much with anyone in my life': Trust and hyperpersonal communication in online friendships. New Media Society 6: 487-506.

Higgins C and Walker R (2012) Egos, logos and pathos: Strategies of persuasion in social/environmental reports. Accounting Forum 36: 194-208.

Hutchby I (1992) The pursuit of controversy: Routine scepticism in talk on 'talk radio'. Sociology 26: 673-694.

Jagatic TN, Johnson NA, Jakobsson M and Menczer F (2007) Social phishing. Communications of the ACM 50(10): 94-100.

Johnson KD (2003) Financial crimes against the elderly. Problem-oriented guides for police: Problemspecific guides series No. 20. US Department of Justice: Office of Community Oriented Policing Services.

Kich M (2005) A rhetorical analysis of fund-transfer-scam solicitations. Cercles 14: 129-142.

Koon TH and Yoong D (2013) Preying on lonely hearts: A systematic deconstruction of an internet romance scammer's online lover persona. Journal of Modern Languages 23: 28-40.

Kunst-Wilson W and Zajonc R (1980) Affective discrimination of stimuli that cannot be recognized. Science 207(4430): 557-558.

Langenderfer J and Shimp TA (2001) Consumer vulnerability to scams, swindles, and fraud: A new theory of visceral influences on persuasion. Psychology \& Marketing 18: 763-783.

Maitlis S and Ozcelik H (2004) Toxic decision processes. Organization Science 15: 375-393.

Mason KA and Benson ML (1996) The effect of social support on fraud victims' reporting behavior: A research note. Justice Quarterly 13: 511-524.

Modic D and Lea SEG (2013) Scam compliance and the psychology of persuasion. Social Science Research Network. Available at: http://dx.doi.org/10.2139/ssrn.2364464 [accessed 10/10/14]. 
Office of Fair Trading (OFT) (2006) Research on impact of mass marketed scams: A summary of research into the impact of scams on UK consumers. OFT 883. http://www.icfs.org.uk/ icfs.org.uk/images/pdfs/60.pdf [accessed 14/01/15].

Ohanian R (1990) Construction and validation of a scale to measure celebrity endorsers' perceived expertise, trustworthiness and attractiveness. Journal of Advertising 19(3): 39-52.

Operation Signature (2013) Sussex Police. http://www.sussex.police.uk/help-centre/ask-us/fraud,scams-andfinancial-issues/what-is-operation-signature [accessed 13/01/2015].

Ross S and Smith RG (2011) Risk factors for advance fee fraud victimization. Trends and Issues in Crime and Criminal Justice 420. Australian Government: Australian Institute of Criminology.

Scambusters (2014) http://www.scambusters.org/scamwords.html [accessed 10/10/14].

Selin C (2006) Trust and the illusive force of scenarios. Futures 38(1): 1-14.

Shivapour S, Nguyen C, Cole C and Denburg N (2002) Effects of age, sex, and neuropsychological performance on financial decision-making. Frontiers in Decision Neuroscience 6(82): 1-15.

Silvia PJ (2005) Deflecting reactance: The role of similarity in increasing compliance and reducing resistance. Basic and Applied Social Psychology 27: 277-284.

Stevens CK and Kristof AL (1995) Making the right impression: A field study of applicant impression management during job interviews. Journal of Applied Psychology 80: 587-606.

Think Jessica (2015) http://www.thinkjessica.com/faqs.htm [accessed 13/01/2015].

Titus RM and Gover AR (2001) Personal fraud: The victims and the scams. Crime Prevention Studies 12: $133-151$.

Yoon C, Cole CA and Lee M (2009). Consumer decision making and aging: Current knowledge and future directions. Journal of Consumer Psychology 19(1): 2-16.

Vergaro C (2004) Discourse strategies of Italian and English sales promotion letters. English for Specific Purposes 23: 181-207.

Whitty MT and Buchanan T (2012) The online dating romance scam: A serious crime. CyberPsychology, Behavior, and Social Networking 15(3): 181-183.

Zajonc RB (1980) Feeling and thinking: Preferences need no inferences. American Psychologist 35(2): 151-175.

Zajonc RB (2001) Mere exposure: A gateway to the subliminal. Current Directions in Psychological Science 10(6): 224-228. 


\section{Author biography}

Elisabeth Carter is a Senior Lecturer in Criminology at Buckinghamshire New University, researching at the intersection of language and the law and taking consultancy work on investigative interviewing and language as evidence. Her book Analysing Police Interviews: Laughter, Confessions and the Tape won the British Society of Criminology's 'Book Prize' 2012. 